\title{
PRODUÇÃO DE MUDAS DE Physocalymma scaberrimum EM SUBSTRATOS COMPOSTOS POR DIFERENTES PORCENTAGENS DE RESÍDUO ORGÂNICO DE AÇAÍ
}

\author{
Álisson Sobrinho Maranho¹, Ary Vieira de Paiva² \\ ${ }^{1}$ Eng. Florestal, Mestrando em Ecologia e Manejo de Recursos Naturais, UFAC, Rio Branco, AC, Brasil - alissonsobrinho@ hotmail.com \\ ${ }^{2}$ Eng. Agrônomo, Dr., Centro de Ciências Biológicas e da Natureza, UFAC, Rio Branco, AC, Brasil - arypaiva1 @ yahoo.com.br
}

Recebido para publicação: 08/10/2010 - Aceito para publicação: 19/02/2012

\begin{abstract}
Resumo
Physocalymma scaberrimum Pohl é uma espécie nativa que ocorre principalmente no Norte e CentroOeste do Brasil, com potencial madeireiro, para arborização urbana e para recomposição de vegetação em áreas degradadas. Considerando a necessidade de conhecimento do seu comportamento em viveiro e da utilização de resíduos agroflorestais como componente de substrato, este estudo teve por objetivo avaliar o crescimento de mudas dessa espécie em substratos compostos por porcentagens de resíduo de açaí $(0 \%, 25 \%, 50 \%, 75 \%, 100 \%)$ misturado à terra de mata. O experimento ocorreu em delineamento inteiramente casualizado, com 5 tratamentos (substratos) e 20 repetições. Foi avaliado o crescimento das mudas através da altura, diâmetro do colo, massa seca da parte aérea e radicular e total, e Índice de Qualidade de Dickson (IQD). Houve ajuste de regressão linear e correlação positiva entre altura, diâmetro do colo e massa seca total com as porcentagens de resíduo de açaí. $\mathrm{O}$ substrato constituído por $100 \%$ do resíduo de açaí proporcionou o maior crescimento das mudas: $32,9 \mathrm{~cm}$ de altura, 2,98 $\mathrm{mm}$ de diâmetro do colo, 2,003 g de massa seca total e maior IQD $(0,1142)$. Para a utilização com terra de mata, a composição entre $25 \%$ e $75 \%$ de resíduo também se mostrou possível. Palavras-chave: Resíduos agroflorestais; produção de mudas; espécies florestais nativas; silvicultura.
\end{abstract}

\begin{abstract}
Physocalymma scaberrimum seedlings production in substrate composed by different percentages of organic residue of açaí. Physocalymma scaberrimum Pohl is a native species that occurs mainly in the North and Midwest regions of Brazil, with potential for wood production, urban forestry and restoration of vegetation in degraded areas. Considering the need for better understanding of the seedlings behavior in the nursery, and use of agroforestry residue as components of substrate, this study aimed to evaluate the growth of this species in substrates composed by different percentages of açaí residue $(0 \%, 25 \%, 50 \%, 75 \%, 100 \%)$ mixed with forest soil. The experiment was set up according to the completely randomized design, with 5 treatments (substrates) and 20 replicates. It was evaluated the growth of seedlings through shoot height, collar diameter, dry weights of shoot and roots and total, and Dickson Quality Index (IQD). A fit linear regression and positive correlation was found out between height, collar diameter and dry weight total dry mass with increasing percentages of açaí residue. The substrate composed by $100 \%$ of açaí residue provided the highest mean growth of seedlings: height $\left(32.9 \mathrm{~cm}^{2}\right.$ seedling $\left.{ }^{-1}\right)$, collar diameter $\left(2.98 \mathrm{~mm}\right.$ seedling $\left.{ }^{-1}\right)$, total dry mass $(2.003 \mathrm{~g}$ seedling $\left.{ }^{-1}\right)$, and highest IQD (0.1142). To use with soil, the composition between $25 \%$ and $75 \%$ of residue also showed possibility.

Keywords: agroforestry residues; seedlings production; native forest species; silviculture.
\end{abstract}

\section{INTRODUÇÃO}

Physocalymma scaberrimum Pohl (Lythraceae) é conhecida popularmente como itaúba-decapoeira, pau-de-rosas e resedá-nacional, entre outras denominações regionais. Ocorre principalmente no Norte e Centro-Oeste do Brasil. Tem porte arbóreo de 5-10 m de altura, dotada de copa alongada ou piramidal, com tronco mais ou menos ereto e cilíndrico, casca rimosa e aspérrima. As folhas são simples, opostas cruzadas (raramente ternadas), rígido-coriáceas, um pouco discolores, aspérrimas em ambas as faces e pubérulas sobre as nervuras na face inferior, de 5-11 cm de comprimento por 2,5-6,5 $\mathrm{cm}$ de 
largura, sobre pecíolo de 2-9 mm de comprimento. Inflorescências em panículas terminais de 10-18 cm de comprimento, com flores muito vistosas, de cor lilás. Os frutos são cápsulas deiscentes, com muitas sementes aladas pequenas. Planta decídua, heliófila, pioneira, produz abundante quantidade de sementes disseminadas pelo vento. A madeira é pesada, muito dura ao corte, com textura grossa, resistente e moderadamente durável, empregada para marcenaria de luxo, serviços de torno, construção civil e para obras externas. A árvore é extremamente ornamental quando em flor, igualando-se à beleza dos ipês, característica esta que a recomenda para uso paisagístico, principalmente para arborização urbana. Também recomendada para reflorestamentos (LORENZI, 1998; CAVALCANTI; GRAHAM, 2012).

A intensificação do uso de espécies florestais que vem ocorrendo na Amazônia nas últimas décadas impõe a necessidade de estudos sobre a sua propagação, com a finalidade de fornecer subsídios para o seu cultivo, tanto para preservação quanto para utilização dessas espécies com os mais variados interesses (MELO; VARELA, 2006).

O êxito dos projetos de reflorestamentos comerciais ou com fins conservacionistas depende, entre outros fatores, da correta escolha das espécies. Devido às múltiplas e complexas interações com o meio, a escolha das espécies será tanto mais correta quanto maior for o conhecimento que se tenha delas, principalmente no que se refere à ecologia e ao seu comportamento silvicultural (CUNHA et al., 2005). Apesar da importância das espécies nativas, poucos são os resultados de pesquisas sobre os seus aspectos silviculturais e autoecológicos que demonstrem seu potencial em programas de reflorestamento ou de recuperação de áreas degradadas (RÊGO; POSSAMAI, 2004), bem como para fins ornamentais, necessitando de pesquisas quanto às suas exigências ao tipo de substrato, luminosidade, temperatura e dimensões de recipiente, entre outros (ARRIGONI-BLANK et al., 2003).

$\mathrm{O}$ uso de uma espécie nativa depende de conhecimentos técnicos a respeito da propagação e do comportamento com relação às variações ambientais. Dados referentes ao tipo de substrato são fundamentais no processo de estabelecimento da muda (NOGUEIRA et al., 2003).

O substrato é definido como o meio em que as plantas são cultivadas fora do solo, considerado como função primordial promover suporte, funcionando ainda como regulador da disponibilidade de nutrientes e de água (KÄMPF, 2000). A escolha do substrato é efetuada em função da facilidade e eficiência do seu uso e da espécie a ser pesquisada (POPINIGIS, 1977).

A propagação de mudas em viveiro tem-se desenvolvido nos últimos anos, buscando-se alternativas de substratos cada vez mais especializados, preocupando-se com a manutenção dos recursos naturais e a redução dos custos. Uma das fontes a que se pode recorrer é a dos resíduos agroflorestais, através dos quais se busca melhorar as condições de crescimento para as espécies, ao mesmo tempo em que é destinado um fim produtivo para esses resíduos, evitando que se tornem poluentes quando descartados de forma incorreta no meio ambiente.

Segundo Sodré et al. (2005), já há exigências de adaptação dos viveiros ao paradigma de substituição de uso do solo por substratos alternativos para a produção comercial de mudas. E afirma Booman (2000) que, em algumas áreas, por razões de conservação do meio ambiente, é proibida a retirada da camada superficial do solo.

O açaí é um produto florestal com potencial econômico que oferece uma variedade de produtos de mercado e de subsistência. No Acre, há duas espécies muito utilizadas comercialmente, Euterpe oleraceae Mart. e Euterpe precatoria Mart. De acordo com dados do Instituto Brasileiro de Geografia e Estatística (IBGE) (2010), a produção nacional de frutos da palmeira açaí em 2010 totalizou 124.421 toneladas. A região Norte lidera na produção do fruto, gerando uma grande quantidade de resíduos que, em sua maioria, são dispostos irregularmente no meio ambiente, podendo tornar-se poluentes quando jogados às margens dos mananciais, causando a depleção das taxas de oxigênio dissolvido na água, pelo aumento da Demanda Bioquímica de Oxigênio (DBO) e eutrofização, entre outros problemas associados.

Diante da importância do estudo das espécies florestais nativas, do pouco conhecimento da propagação de Physocalymma scaberrimum Pohl em viveiro e do uso dos resíduos agroflorestais como substrato, o estudo teve por objetivo avaliar o crescimento dessa espécie em substratos compostos por diferentes porcentagens de resíduo orgânico de açaí misturado à terra de mata.

\section{MATERIAL E MÉTODOS}

O estudo ocorreu no Viveiro de Produção de Mudas, no Parque Zoobotânico da Universidade Federal do Acre (UFAC), no interior de casa de vegetação. 
As sementes utilizadas foram coletadas no mês de novembro de 2009, no Parque Zoobotânico da UFAC, levadas até o viveiro e armazenadas em saco plástico transparente em câmara fria $\left(\approx 13^{\circ} \mathrm{C}\right)$ por 15 dias, até a instalação do experimento.

Primeiramente, foi realizada a semeadura em substrato areia, em bandejas de plástico, a $1 \mathrm{~cm}$ de profundidade, no espaçamento $2 \times 2 \mathrm{~cm}$, até as plântulas atingirem tamanho suficiente para a repicagem $(\approx 10 \mathrm{~cm})$ para os devidos substratos em teste, que foram dispostos em sacos plásticos de polietileno preto com dimensões 17 x $25 \mathrm{~cm}$, e uma muda por recipiente.

O experimento consistiu no transplantio de mudas da espécie em estudo para os sacos plásticos, contendo substratos compostos por diferentes porcentagens de resíduo de açaí $(0 \%, 25 \%, 50 \%, 75 \%$, $100 \%$ ) misturados à terra de mata, conduzido em delineamento inteiramente casualizado, com 5 tratamentos e 20 repetições, totalizando 100 unidades amostrais.

A preparação da terra de mata ocorreu de acordo com a análise realizada pelo Laboratório de Fertilidade do Solo da UFAC (Tabela 1), atendendo a recomendação de adubação e calagem (1,5 t.ha ${ }^{-1}$ de calcário; 54,8 kg.ha ${ }^{-1}$ de $\mathrm{P}_{2} \mathrm{O}_{5} ; 31,3 \mathrm{~kg} \cdot \mathrm{ha}^{-1}$ de $\mathrm{K}_{2} \mathrm{O}$ ).

Tabela 1. Análise de fertilidade da terra de mata utilizada na composição dos substratos, antes da adubação e calagem recomendada.

Table 1. Analysis of forest soil fertility for composition of the substrates before fertilization and recommended liming.

\begin{tabular}{|c|c|}
\hline & Resultado analítico \\
\hline pH (água 1:2,5) & 4,10 \\
\hline $\mathrm{Ca}^{+2}\left(\mathrm{cmol}_{\mathrm{c}} \cdot \mathrm{dm}^{3}\right)$ & 0,75 \\
\hline $\mathrm{K}^{+}\left(\mathrm{cmol}_{\mathrm{c}} \cdot \mathrm{dm}^{3}\right)$ & 0,15 \\
\hline $\mathrm{Na}^{+}\left(\mathrm{cmol}_{\mathrm{c}} \cdot \mathrm{dm}^{3}\right)$ & 0,02 \\
\hline $\mathrm{Mg}^{+2}\left(\mathrm{cmol}_{\mathrm{c}} \cdot \mathrm{dm}^{3}\right)$ & 0,50 \\
\hline $\mathrm{Al}^{+3}\left(\mathrm{cmol}_{\mathrm{c}} \cdot \mathrm{dm}^{3}\right)$ & 0,90 \\
\hline $\mathrm{Al}^{+3}+\mathrm{H}^{+}\left(\mathrm{cmol}_{\mathrm{c}} \cdot \mathrm{dm}^{3}\right)$ & 2,69 \\
\hline $\mathrm{P}\left(\mathrm{mg} \cdot \mathrm{dm}^{3}\right)$ & 3,00 \\
\hline
\end{tabular}

O resíduo orgânico de açaí, oriundo do beneficiamento do fruto para produção de polpa, utilizado no experimento foi coletado no viveiro da UFAC, posto para secagem à temperatura ambiente $\mathrm{e}$ mais tarde peneirado para separação das sementes. O que foi utilizado neste estudo foi uma borra que permanece na semente após a retirada da polpa do fruto do açaí. Posteriormente realizou-se a mistura dos materiais para a composição dos substratos.

A tabela 2 mostra a análise química do resíduo de açaí utilizado no experimento, realizada pelo Laboratório do Departamento de Ciência do Solo da ESALQ/USP.

Tabela 2. Determinações dos totais dos nutrientes presentes no resíduo orgânico de açaí utilizado no experimento.

Table 2. Determinations of nutrient totals present in açai organic residue utilized in the experiment.

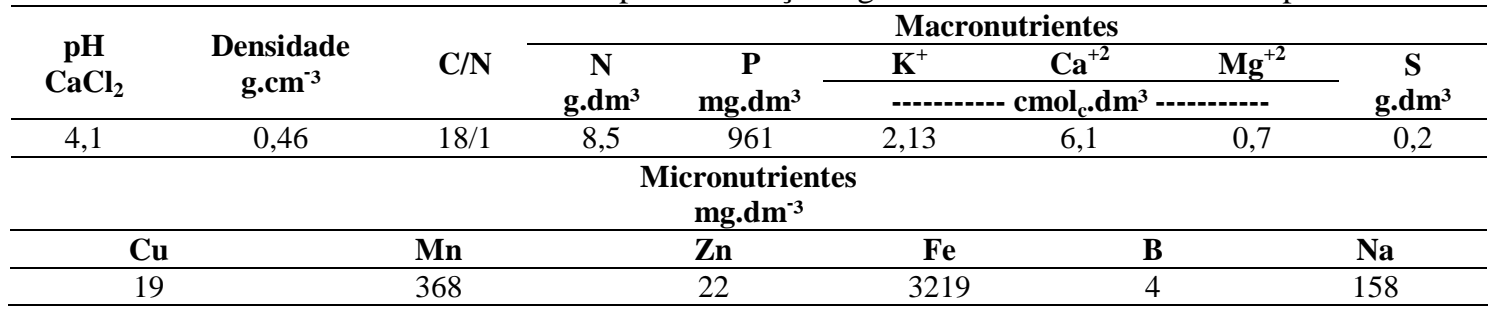

A irrigação ocorreu diariamente, considerando a umidade relativa do ar, estágio médio de desenvolvimento das mudas e a quantidade máxima que o substrato pode reter, homogeneamente para todos os substratos.

As características utilizadas para avaliação do crescimento das mudas foram Altura da Parte Aérea (H) e Diâmetro do Colo (DC), e ao final do experimento (90 dias da data do transplantio) foi 
realizada a coleta do material, sendo determinadas a Massa Seca Total (MST), Massa Seca da Parte Aérea (MSPA), Massa Seca das Raízes (MSR), a relação entre Altura da Parte Aérea e o Diâmetro do Colo (H/D) e o Índice de Qualidade de Dickson (IQD).

A $\mathrm{H}$ foi medida com um escalímetro, a partir do nível do substrato até a altura da gema apical, e o DC, por um paquímetro digital com precisão de $0,01 \mathrm{~mm}$. A relação H/D foi determinada pela simples divisão entre os dois parâmetros, de cada muda individualmente, calculando-se, posteriormente, as médias. As determinações da MSPA e da MSR foram efetuadas a partir do material seco em estufa de ventilação forçada a $80{ }^{\circ} \mathrm{C}$, por aproximadamente 24 horas. A MST foi obtida a partir da soma das duas partes. O Índice de Qualidade de Dickson (IQD = $[\mathrm{MST} /(\mathrm{H} / \mathrm{DC}+\mathrm{MSPA} / \mathrm{MSR})]$ ) foi calculado conforme citado por Carneiro (1995).

Os dados foram submetidos à análise de variância, teste de regressão, de normalidade, ao teste $\mathrm{F}$ de Snedecor, e as médias foram comparadas pelo teste de Tukey ao nível de $5 \%$ de probabilidade. Os dados, quando não apresentaram normalidade foram transformados para homogeneização dos resultados (SANTANA; RANAL, 2004), porém os apresentados nas tabelas são os dados originais. Para todas as análises foram utilizados os programas estatísticos Assistat 7.5 (ASSIS, 2008), e Bioestat 5.0 (AYRES, 2007).

\section{RESULTADOS E DISCUSSÃO}

Constatou-se que houve efeito dos substratos sobre o crescimento das mudas de Physocalymma scaberrimum, quando avaliadas aos 90 dias após o transplantio (Tabela 3).

Tabela 3. Crescimento médio em Altura (H), Diâmetro do Colo (DC) e relação H/D das mudas de Physocalymma scaberrimum aos 90 dias após o transplantio.

Table 3. Mean growth in Height (H), Collar Diameter (DC) and H/D ratio of Physocalymma scaberrimum plantlets 90 days after transplanting.

\begin{tabular}{|c|c|c|c|}
\hline Substratos & $\mathrm{H}\left(\mathrm{cm} \cdot \mathrm{muda}^{-1}\right)$ & DC $\left(\mathrm{mm} \cdot \mathrm{muda}^{-1}\right)$ & Relação H/D \\
\hline $0 \% \mathrm{RA}^{*}$ & $21,9 \mathrm{c}$ & $2,35 \mathrm{~b}$ & $9,53 \mathrm{a}$ \\
\hline $25 \%$ RA & $26,5 \mathrm{bc}$ & $2,65 \mathrm{ab}$ & $10,19 \mathrm{a}$ \\
\hline $50 \%$ RA & $27,5 \mathrm{ab}$ & $2,44 \mathrm{~b}$ & $11,43 \mathrm{a}$ \\
\hline $75 \% \mathrm{RA}$ & $26,9 \mathrm{bc}$ & $2,64 \mathrm{ab}$ & 10,36 a \\
\hline $100 \%$ RA & 32,9 a & $2,98 \mathrm{a}$ & $11,11 \mathrm{a}$ \\
\hline $\mathrm{CV}(\%)$ & 21,93 & 20,76 & 21,26 \\
\hline
\end{tabular}

*RA: resíduo de açaí; as médias seguidas pelas mesmas letras não diferem entre si significativamente, pelo teste de Tukey, ao nível de $5 \%$ de probabilidade; CV: coeficiente de variação.

Verifica-se que houve diferença significativa entre as diferentes composições de substrato para o crescimento em altura e diâmetro do colo das mudas. A relação H/D não se diferenciou estatisticamente entre os substratos.

O substrato $100 \%$ de resíduo de açaí proporcionou o maior crescimento médio em altura das mudas, igualando-se apenas ao substrato $50 \%$ de resíduo de açaí. A testemunha (0\% RA) proporcionou o menor crescimento médio em altura das mudas.

Segundo Mexal e Landis (1990), a altura da parte aérea fornece uma boa estimativa do crescimento inicial da mudas no campo, sendo tecnicamente aceita como uma boa medida do potencial de desempenho.

Diversos trabalhos vêm alcançando bons resultados com a utilização de outros tipos de substratos à base de resíduos, como pó ou fibra de coco verde (DIAS et al., 2009; LACERDA et al., 2006), casca de arroz carbonizada (NICOLOSO et al., 2000; SAIDELLES et al., 2009), casca de árvores (SCHMITZ et al., 2002), pó de serragem (ALMEIDA et al., 1999) e vários tipos de compostos com restos vegetais (CUNHA et al., 2005; MUNIZ et al., 2007), entre outros.

Lacerda et al. (2006) observaram que mudas de Mimosa caesalpiniifolia Benth obtiveram expressivo ganho em altura quando cultivadas em substrato à base de pó de coco verde e terra, o que também foi observado por Saidelles et al. (2009) em mudas de Enterolobium contortisiliquum (Vell.) 
Morong produzidas em substrato produzido a partir da combinação de casca de arroz carbonizada com terra $(1: 1 \mathrm{v} / \mathrm{v})$.

$\mathrm{O}$ incremento em altura da parte aérea das mudas foi medido a cada trinta dias após o transplantio, conforme exposto na figura 1 .

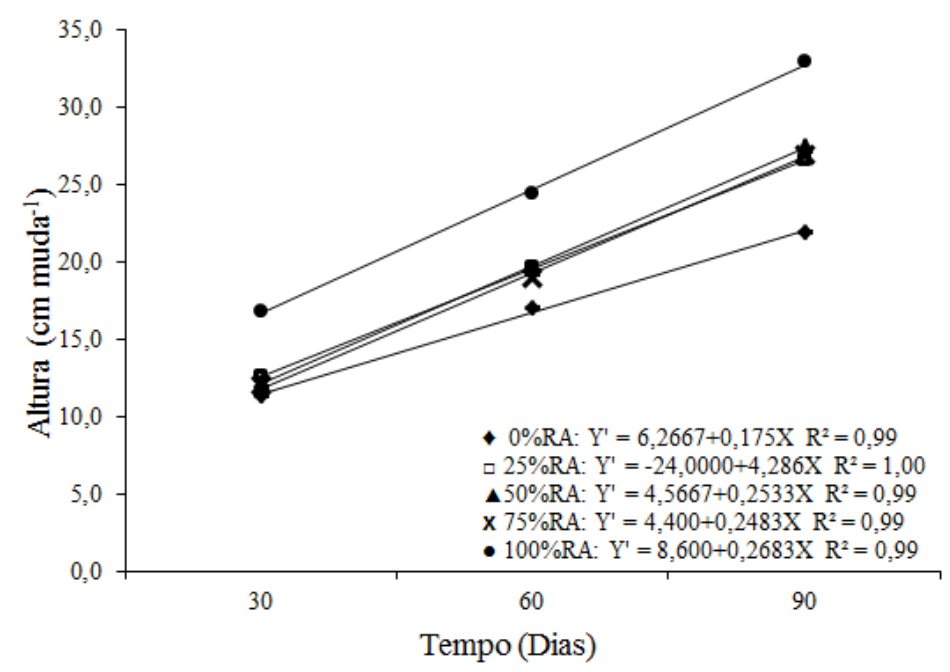

Figura 1. Crescimento médio em altura das mudas de Physocalymma scaberrimum, aos 30, 60 e 90 dias após o transplantio, nos diferentes substratos à base de Resíduo de Açaí (RA).

Figure 1. Mean height growth of Physocalymma scaberrimum seedlings at 30, 60 and 90 days after the transplanting in different substrates of Açai Residues (RA).

O crescimento em altura das mudas da espécie em estudo foi bem expressivo em todos os substratos (Figura 1). No entanto, aos trinta dias, as mudas em substrato 100\% resíduo de açaí já se apresentavam superiores às demais, com altura acima de $15 \mathrm{~cm}$.muda ${ }^{-1}$, e assim progressivamente durante todo o experimento.

As mudas nos substratos $25 \%$ RA, $50 \%$ RA e $75 \%$ RA se mantiveram com crescimento em altura semelhante durante todo o período, mas ainda inferiores ao substrato 100\%RA e superiores ao 0\%RA, que se manteve inferior a todos os outros durante todo o ensaio.

Por ser a espécie Physocalymma scaberrimum uma pioneira, esse crescimento rápido é evidente, haja vista que, segundo Gonçalves et al. (2000), as espécies dos estágios iniciais de sucessão apresentam maiores taxas de crescimento e demandas por nutriente. Nesse sentido, pode-se observar pela tabela 3 que as mudas investiram mais em altura do que em diâmetro do colo, como verificado através da relação H/D, que foi alta para todos os substratos e estatisticamente iguais entre si.

Em relação ao crescimento em diâmetro do colo (Tabela 3), a maior média foi obtida no substrato $100 \% \mathrm{RA}$, e a menor no substrato $0 \% \mathrm{RA}$, semelhante à altura da parte aérea. O incremento diamétrico também foi medido a cada trinta dias após o transplantio, como se pode verificar na figura 2.

As médias dos diâmetros dos colos seguiram a tendência de crescimento das alturas. Aos trinta dias, as mudas no substrato 100\%RA já apresentavam média de diâmetro do colo superior às demais, mantendo-se até os noventa dias de observação. Os substratos 25\%RA e 75\%RA também proporcionaram elevado incremento médio de diâmetro do colo durante esse período.

Nicoloso et al. (2000) também encontraram diferença de comportamento de diâmetros do colo, estudando o crescimento em viveiro de mudas de Apuleia leiocarpa (Vogel) J.F.Macbr. e Maytenus ilicifolia Mart. ex Reissek, porém em substrato constituído por mistura de casca de arroz carbonizada e terra $(1: 1 \mathrm{v} / \mathrm{v})$. Resultado semelhante foi obtido por Cunha et al. (2005) com mudas de Handroanthus impetiginosus Mattos em substrato terra de solo mais composto orgânico (1:1 v/v) de bagaço de cana-deaçúcar, esterco bovino, esterco de galinha e cinzas.

A produção de massa seca é uma característica bastante consistente e utilizada na avaliação do comportamento das espécies quanto às variações dos fatores externos, como o substrato (Tabela 4). 


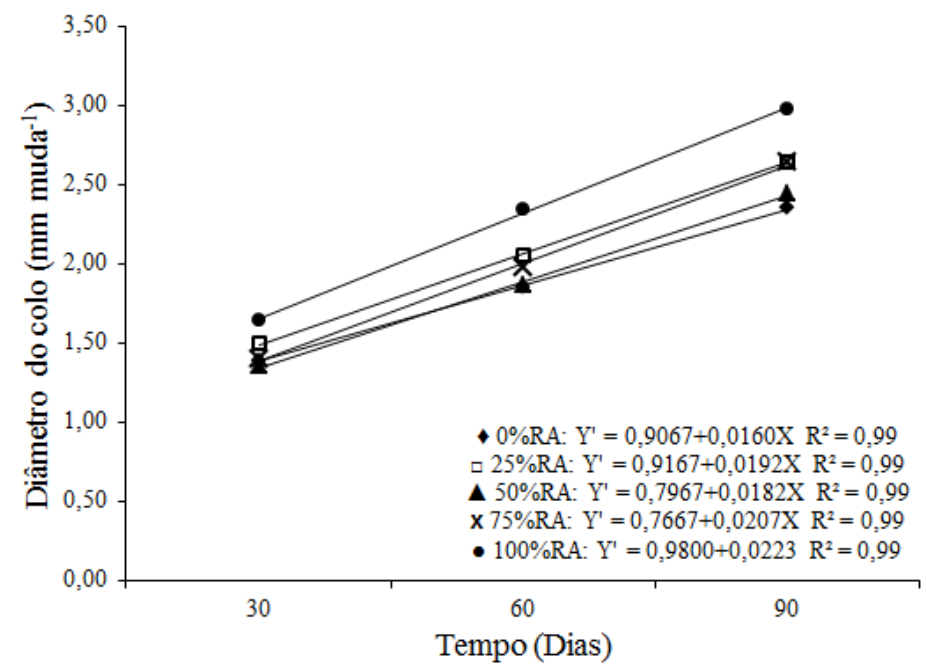

Figura 2. Crescimento médio em diâmetro do colo das mudas de Physocalymma scaberrimum aos 30, 60 e 90 dias após o transplantio, nas diferentes doses de resíduo de açaí.

Figure 2. Mean collar diameter growth of Physocalymma scaberrimum seedlings at 30,60 and 90 days after the transplanting, at different dosage of açai residue.

Verifica-se que houve diferença significativa entre os efeitos dos substratos para a produção de massa seca da parte aérea, de raiz, total e o Índice de Qualidade de Dickson.

A maior produção média de MST foi obtida pelas mudas cultivadas em substrato 100\%RA, igualando-se estatisticamente apenas ao substrato 25\%RA. A MSPA e MSR foram superiores também para mudas no substrato 100\%RA, seguido dos demais substratos, que foram estatisticamente semelhantes aos 90 dias do transplantio. Resultados semelhantes foram observados por Dias et al. (2009) em mudas de Hancornia speciosa Gomes em substrato associado com terra vegetal e fibra de coco.

Tabela 4. Produção média de massa seca (g.muda ${ }^{-1}$ ) da parte aérea (MSPA), de raiz (MSR) e total (MST) e Índice de Qualidade de Dickson (IQD) de Physocalymma scaberrimum aos 90 dias após o transplantio.

Table 4. Mean dry weights (g.seedling ${ }^{-1}$ ) of shoot (MSPA), roots (MSR), and total (MST), and Dickson Quality Index (IQD) of Physocalymma scaberrimum seedlings, 90 days after the transplanting.

\begin{tabular}{lcccc}
\hline Substratos & MSPA & MSR & MST & IQD \\
\hline $0 \%$ RA* & $0,954 \mathrm{~b}$ & $0,197 \mathrm{ab}$ & $1,151 \mathrm{~b}$ & $0,0848 \mathrm{ab}$ \\
$25 \%$ RA & $1,363 \mathrm{ab}$ & $0,183 \mathrm{ab}$ & $1,545 \mathrm{ab}$ & $0,0872 \mathrm{ab}$ \\
$50 \%$ RA & $1,061 \mathrm{~b}$ & $0,106 \mathrm{~b}$ & $1,167 \mathrm{~b}$ & $0,0553 \mathrm{~b}$ \\
$75 \%$ RA & $1,176 \mathrm{~b}$ & $0,131 \mathrm{~b}$ & $1,306 \mathrm{~b}$ & $0,0678 \mathrm{~b}$ \\
$100 \%$ RA & $1,738 \mathrm{a}$ & $0,266 \mathrm{a}$ & $2,003 \mathrm{a}$ & $0,1142 \mathrm{a}$ \\
$\mathrm{CV}(\%)$ & 16,49 & 66,18 & 17,15 & 58,22 \\
\hline
\end{tabular}

*RA: resíduo de açaí; as médias seguidas pelas mesmas letras não diferem entre si significativamente, pelo teste de Tukey, ao nível de $5 \%$ de probabilidade; $\mathrm{CV}$ : coeficiente de variação.

O Índice de Qualidade de Dickson (Tabela 4), que diz respeito à qualidade das mudas e que leva em consideração várias características, mostrou maiores valores para as mudas de Physocalymma scaberrimum cultivadas em substrato $100 \%$ RA.

Observa-se que houve uma tendência de aumento dos resultados para as características de crescimento observadas nas mudas da espécie em avaliação na medida em que se aumentou a dose de resíduo (Figura 3).

A equação mais bem ajustada foi de regressão linear simples para a altura, diâmetro do colo e produção de massa seca total das plântulas. Nota-se, pela figura 3, que as mudas de Physocalymma 
scaberrimum responderam de modo significativo às aplicações de resíduo de açaí, o que pode ser atribuído às melhores condições de fertilidade do substrato.
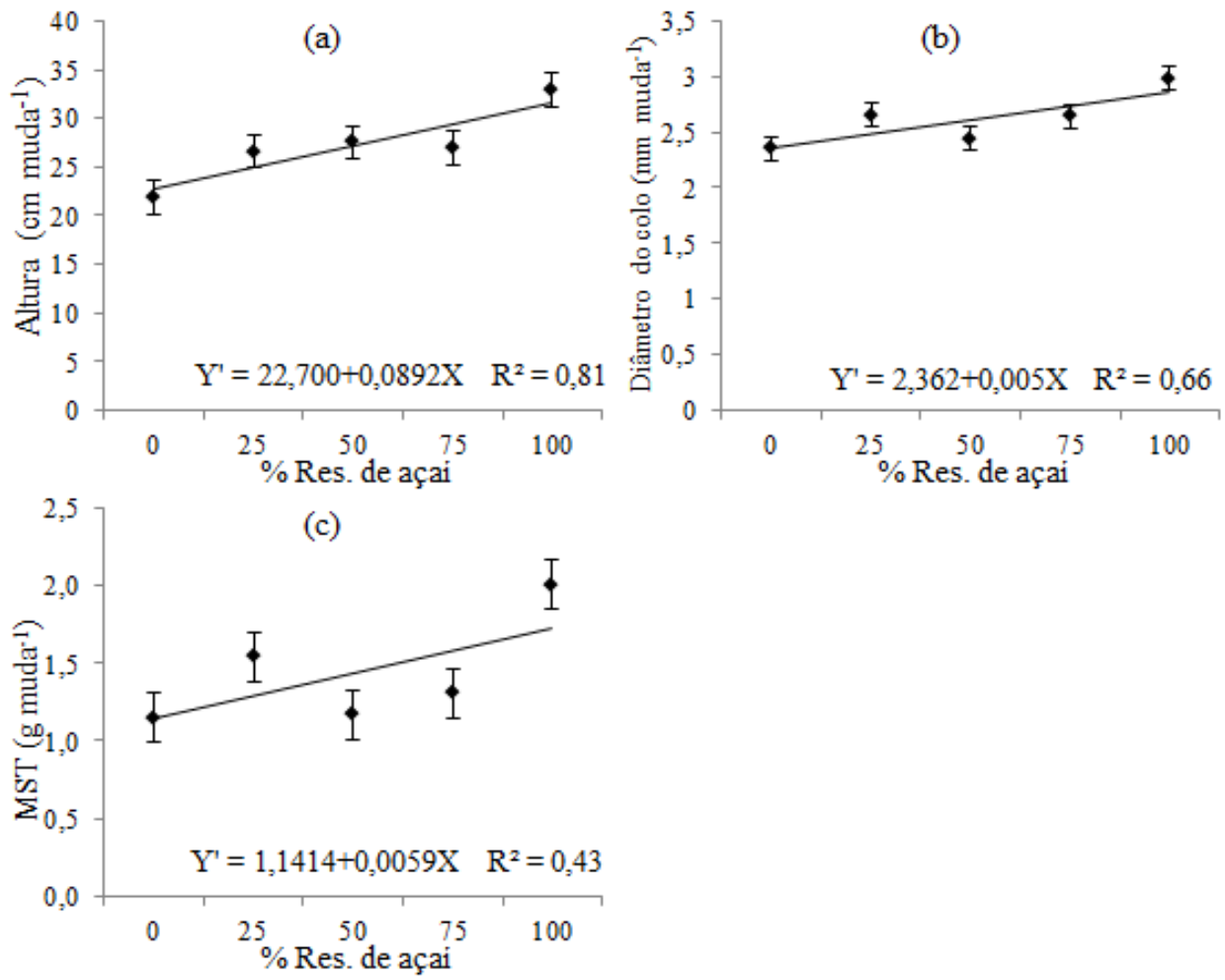

Figura 3. Análise de regressão simples entre altura (a), diâmetro do colo (b), massa seca total - MST (c) das mudas de Physocalymma scaberrimum com as doses crescentes de resíduo de açaí.

Figure 3. Simple regression analysis between height (a), collar diameter (b), dry mass weight total MST (c) of Physocalymma scaberrimum seedlings with increasing dosage of açai residue.

A propósito da Correlação Linear de Pearson, verifica-se que ela foi altamente positiva para altura $(\mathrm{r}=0.90)$, diâmetro do colo $(\mathrm{r}=0.81)$ e produção de massa seca total $(\mathrm{r}=0.65)$, demonstrando relação significativa entre essas características de crescimento das mudas com as doses crescentes de resíduo, aumentando progressivamente na medida em que se aumentou a porcentagem de resíduo de açaí como componente de substrato. Então, em comparação com o substrato testemunha (100\% terra de mata), o resíduo de açaí pode substituí-lo em parte ou totalmente para a propagação de mudas dessa espécie, nessa fase inicial de crescimento.

\section{CONCLUSÕES}

- O resíduo orgânico de açaí influenciou positivamente o crescimento das mudas de Physocalymma scaberrimum Pohl.

- Em todas as características avaliadas, os melhores resultados foram obtidos em mudas cultivadas no substrato $100 \%$ resíduo de açaí.

- A equação mais bem ajustada foi de regressão linear simples, apresentando correlação positiva entre altura, diâmetro do colo e peso de massa seca total com as porcentagens de resíduo orgânico de açaí misturado à terra de mata. 


\section{REFERÊNCIAS}

ALMEIDA, M. de C.; FIRMINO, J. L.; RIGAMONTE-AZEVEDO, O. C. Efeito da camada de cobertura na emergência e no desenvolvimento de plântulas de amarelão (Aspidosperma vargasii A.DC. Apocynaceae). Revista Brasileira de Sementes, Londrina, v. 21, n. 2, p. 43 - 46, 1999.

ARRIGONI-BLANK, M. de F.; CARVALHO FILHO, J. L. S. de; BLANK, A. F.; SANTOS NETO, A. L. dos. Efeitos do substrato e luminosidade na emergência e desenvolvimento de mudas de jasmimlaranja (Murraya exotica). Revista Ciência Agronômica, v. 34, n. 1, p. 5 - 12, 2003.

ASSIS, F. de. Assistat 7.5. Departamento de Engenharia Agrícola, UFCG. Disponível em: <http://www.assistat.com>. Acesso em: 15/06/2009.

AYRES, M. Bioestat: aplicações estatísticas nas áreas de ciências biológicas e médicas. Belém: Sociedade Civil Mamirauá, MCT-CNPq. Disponível em: 〈http://www.mamiraua.org.br/downloads/>. Acesso em: 15/06/2009.

BOOMAN, J. L. Evolução dos substratos usados em horticultura ornamental na Califórnia. In: KÄMPF, A. N.; FERMINO, M. H. Substratos para plantas: a base de produção vegetal em recipientes. Porto Alegre, 2000. p. 43 - 65.

CARNEIRO, J. G. de A. Produção e controle de mudas florestais. Curitiba: UFPR/FUPEF, 1995. 451 p.

CAVALCANTI, T. B.; GRAHAM, S. Lythraceae in lista de espécies da flora do Brasil. Jardim Botânico do Rio de Janeiro. Disponível em: <http://floradobrasil.jbrj.gov.br/2012/FB023480>. Acesso em: $14 / 02 / 2012$.

CUNHA, A. O.; ANDRADE, L. A. de; BRUNO, R. de L. A.; SILVA, J. A. L. da; SOUZA, V. C. de. Efeitos de substratos e das dimensões dos recipientes na qualidade das mudas de Tabebuia impetiginosa (Mart. Ex D.C.) Standl. Revista Árvore, Viçosa, v. 29, n. 4, p. 507 - 516, 2005.

DIAS, T. J.; PEREIRA, W. E.; CAVALCANTE, L. F.; RAPOSO, R. W. C.; FREIRE, J. L. de O. Desenvolvimento e qualidade nutricional de mudas de mangabeiras cultivadas em substratos contendo fibra de coco e adubação fosfatada. Revista Brasileira de Fruticultura, Jaboticabal, v. 31, n. 2, p. 512 $523,2009$.

GONÇALVES, J. L. de M.; SANTARELli, E. G.; MORAES NETO, S. P. de; MANARA, M. P. Produção de mudas de espécies nativas: substrato, nutrição, sombreamento e fertilização. In: GONÇALVES, J. L. de M.; BENEDETTI, V. Nutrição e Fertilização Florestal. Piracicaba, 2000. p. 310 - 349 .

INSTITUTO BRASILEIRO DE GEOGRAFIA E ESTATÍSTICA (IBGE). Produção da Extração Vegetal e da Silvicultura. Rio de Janeiro, 2010. v. 25. 50 p.

KÄMPF, A. N. Seleção de materiais para uso como substrato. In: KÄMPF, A. N.; FIRMINO, M. H. Substratos para plantas: a base da produção vegetal em recipientes. Porto Alegre, 2000. p. 209 - 215.

LACERDA, M. R. B. L.; PASSOS, M. A. A.; RODRIGUES, J. J. V.; BARRETO, L. P. Características físicas e químicas de substratos à base de pó de coco e resíduo de sisal para produção de mudas de sabiá (Mimosa caesalpiniifolia Benth). Revista Árvore, Viçosa, v. 30, n. 2, p. 163 - 170, 2006.

LORENZI, H. Árvores Brasileiras: manual de identificação e cultivo de plantas arbóreas nativas do Brasil. Nova Odessa: Editora Plantarum, 1998. v. 2. 2. ed. 384 p.

MEXAL, J. L.; LANDIS, T. D. Target seedling concepts: height and diameter. In: TARGET SEEDLING SYMPOSIUM, COMBINED MEETING OF THE WESTERN FOREST NURSERY ASSOCIATIONS. 1990, Roseburg. Proceedings... Fort. Collins: USDA, Forest Service, 1990. p. 17 - 35.

MELO, M. de F. F.; VARELA, V. P. Aspectos morfológicos de frutos, sementes, germinação e plântulas de duas espécies florestais da Amazônia. I. Dinizia excelsa Ducke (angelim-pedra). II Cedrelinga catenaeformis Ducke (cedrorana) - Leguminosae: Mimosoideae. Revista Brasileira de Sementes, v. 28, n. 1, p. $54-62,2006$. 
MUNIZ, M. F. B.; SILVA, L. M. e; BLUME, E. Influência da assepsia e do substrato na qualidade de sementes e mudas de espécies florestais. Revista Brasileira de Sementes, Londrina, v. 29, n. 1, p. 140 146, 2007.

NICOLOSO, F. T.; FORTUNATO, R. P.; ZANCHETTI, F.; CASSOL, L. F.; EISINGER, S. M. Recipientes e substratos na produção de mudas de Maytenus ilicifolia e Apuleia leiocarpa. Ciência Rural, Santa Maria, v. 30, n. 6, p. 987 - 992, 2000.

NOGUEIRA, R. J. M. C.; ALBUQUERQUE, M. B. de; SILVA JÚNIOR, J. F. Efeito do substrato na emergência, crescimento e comportamento estomático em plântulas de mangabeira. Revista Brasileira de Fruticultura, Jaboticabal, v. 25, n. 1, p. 15 - 18, 2003.

POPINIGIS, F. Fisiologia da semente. Brasília: AGIPLAN, 1977. 289 p.

RÊGO, G. M.; POSSAMAI, E. Efeito do substrato e da temperatura sobre a germinação e vigor de sementes do jequitibá-rosa (Cariniana legalis). Colombo: EMBRAPA, 2004. (Comunicado Técnico, 127).

SAIDELLES, F. L. F.; CALDEIRA, M. V. W.; SCHIRMER, W. N.; SPERANDIO, H. V. Casca de arroz carbonizada como substrato para produção de mudas de tamboril-da-mata e garapeira. Ciências Agrárias, Londrina, v. 30, n. 1, p. 1173 - 1186, 2009.

SANTANA, D. de G.; RANAL, M. A. Análise da germinação: Um enfoque estatístico. Brasília: Universidade de Brasília, 2004. 248 p.

SCHMITZ, J. A. K.; SOUZA, P. V. D. de; KÄMPF, A. N. Propriedades químicas e físicas de substratos de origem mineral e orgânica para o cultivo de mudas em recipientes. Ciência Rural, v. 32, n. 6, 2002.

SODRÉ, G. A.; CORÁ, J. E.; BRANDÃO, I. C. S. F. L.; SERÔDIO, M. H. de C. F. Características químicas de substratos utilizados na produção de mudas de cacaueiros. Revista Brasileira de Fruticultura, Jaboticabal, v. 27, n. 3, p. 514 - 516, 2005. 
